\title{
Estratégias Competitivas para Empresas de Rochas Ornamentais na Região Metropolitana do Rio de Janeiro
}

Competitive Strategies for

Dimensional Stone Companies in the Rio de Janeiro Metropolitan Area

\author{
Claudio Margueron \& Edson Farias Mello
}

\begin{abstract}
UFRJ, Departamento de Geologia, CCMN/IGEO, Cidade Universitária - Ilha do Fundão, 21949-900. Rio de Janeiro, RJ - Brasil. e-mail:margueron@geologia.ufrj.br,mello@geologia.ufrj.br

Recebido em:13/11/2005 Aprovado em: 18/11/2005
\end{abstract}

\section{Resumo}

A estratégia para acelerar o desenvolvimento de lavra, beneficiamento, tecnologia, competitividade e gestão de empresas de rochas ornamentais envolve várias análises e metodologias alternativas. Neste projeto usou-se a metodologia matriz do Ciclo de Vida com seus principais fatores externos (maturidade da indústria) e internos (medida global da posição competitiva de um negócio) para analisar em detalhe o setor de serrarias da região metropolitana do Rio de Janeiro e a posição competitiva das principais empresas que atuam no setor. Especial importância foi dada ao processo produtivo de chapas de rochas ornamentais, mostrando os principais métodos de beneficiamento de blocos e beneficiamento secundário. Um Estudo de Caso foi usado como base de dados para a adoção e seleção de estratégias para as serrarias localizadas na região metropolitana do Rio de Janeiro. As seguintes serrarias foram descritas com especial atenção à sua infra-estrutura, organização, capacidade instalada de produção, linha de produção de chapas de granito, fatores críticos de sucesso, tecnologia, insumos, integração vertical, vendas, fatias de mercado e qualidade dos produtos: Thor, Brasilstone, Rio Segran, Gutimpex, Cavaliere, Belmonte, Real Brasil e Marcovaldi. Foram identificadas futuras possíveis grandes opções estratégicas - programas de ação - estratégias funcionais e planos de ação para acelerar o desenvolvimento das empresas de rochas ornamentais 
na região metropolitana do Rio de Janeiro. Um diagnóstico estratégico também foi realizado e será valioso para as empresas e empresários que já atuam no setor e para as novas empresas e novos investidores nacionais e estrangeiros que possam vir a ter interesse em investir neste setor no curto e médio prazos. Palavras-chave: Rochas ornamentais, estratégias competitivas, economia mineral, região metropolitana do Rio de Janeiro.

\section{Abstract}

The strategy to accelerate the development of mining-beneficiationtechnology-competitivity management of dimension stone companies involves various analysis and alternative methodologies. In this project the Life-Cycle Matrix methodology was used with its main external (industry maturity) and internal (overall measure of the competitive position of a business) factors to analyze in detail the block cutting (sawing) sector of the metropolitan region of Rio de Janeiro and the competitive position of the main companies that are active in the sector. Special attention was given to the dimension stone plates production process, describing the main methods used to beneficiate blocks and to undertake secondary beneficiation. A Case Study was used as the data base for the adoption and selection of strategies for the block cutting companies located in the metropolitan region of Rio de Janeiro. The following block sawing companies were described with special attention to their infra-structure, organization, installed production capacity, granite plates production lines, critical success factors, technology, inputs, vertical integration, sales, market share, and products quality: Thor, Brasilstone, Rio Segran, Gutimpex, Cavaliere, Belmonte, Real Brasil and Marcovaldi. The objective of identifying future possible main strategic thrusts-action programs-functional strategies and action plans to accelerate the development of the dimension stone companies in the metropolitan region of Rio de Janeiro was achieved. A Strategy Diagnostic Study also was undertaken and will be of great value for the companies and entrepreneurs that are already active in the sector and for the new national and foreign companies and new investors that may have interest to invest in this sector in short and medium time periods.

Keywords: Dimension stone, competitive strategies, Rio de Janeiro.

\section{Introdução}

O setor de rochas ornamentais no Rio de Janeiro e no Brasil está condicionado a vários processos de reestruturação institucional, bem como de 


\section{Estratégias Competitivas para Empresas de Rochas Ornamentais na Região Metropolitana do Rio de Janeiro \\ Claudio Margueron \& Edson Farias Mello}

integração competitiva na economia mundial. Conseqüentemente, no âmbito governamental e no âmbito empresarial, os processos de planejamento estratégico e de tomada de decisão devem estar apoiados por completos e atualizados sistemas de informação e bases de dados que ofereçam parâmetros de referência relativos aos fatores estruturais (técnicos, econômicos, operacionais e gerenciais) e sistêmicos (institucionais, ambientais, legais, infraestruturais, fiscais e financeiros) necessários à análise e ao posicionamento competitivo das empresas mineradoras e de beneficiamento de rochas ornamentais relativamente aos seus principais competidores no Brasil e no exterior.

O Estado do Rio de Janeiro produz aproximadamente 5\% da produção brasileira de granito, mármore e pedra miracema. No ano de 2000 produziu aproximadamente 260.000 toneladas de rochas ornamentais subdivididas em 65.000 toneladas/ano de granito (25\%), 13.000 toneladas/ano de mármore (5\%) e 182.000 toneladas/ano de pedra miracema (75\%), de acordo com a ABIROCHAS (2001). No Estado do Rio de Janeiro existem cerca de 150 teares instalados (7\% do total brasileiro). Estima-se que 20\% destes teares estejam parados atualmente. A maior parte das 230 frentes de lavra (33\% do total nacional) existentes no Rio de Janeiro estão localizadas em Santo Antônio de Pádua. Estima-se que o número de pedreiras de pedra miracema em Pádua alcance a cifra de 200. A mão-de-obra direta ocupada no setor de rochas ornamentais no Estado do Rio de Janeiro é estimada em aproximadamente 15.000 (14\% do total brasileiro).

Até 1990, o Estado do Rio de Janeiro era o segundo maior produtor e exportador de rochas ornamentais do País. A década de noventa foi um período de crise para o setor devido a mudanças na política tributária, ambiental e de uso e ocupação do solo, dos governos municipal, estadual e federal. Nos últimos anos a situação tem melhorado gradativamente para o setor de rochas ornamentais. $\mathrm{O}$ atual momento econômico brasileiro é favorável a novos investimentos em vários setores de produção. Conseqüentemente, o setor de rochas ornamentais do município e da região metropolitana do Rio de Janeiro está se preparando para retomar os investimentos, especialmente na produção e exportação de manufaturados. Os empresários do setor de rochas ornamentais contatados recomendam que sejam feitos estudos estratégicos para acelerar o desenvolvimento de lavra, beneficiamento, tecnologia, competitividade, gestão da empresas que atuam neste ramo de atividade econômica no município e na região metropolitana do Rio de Janeiro. Esta publicação é apenas um sumário do que vem sendo realizado nestes últimos anos.

Este estudo teve por objetivo estudar as estratégias a serem adotadas 
pelas principais empresas de rochas ornamentais do município e da região metropolitana do Rio de Janeiro para melhorar e acelerar o desenvolvimento da exploração-lavra-beneficiamento, comercialização nacional e internacional, e adicionar valor para seus stakeholders internos (empregados, dirigentes) e externos (clientes, acionistas, compradores ou consumidores, fornecedores, etc.). Para tanto foi utilizada uma base de dados com informações já disponíveis, e outros insumos coletados durante o período de vigência do trabalho. O enfoque estratégico-competitivo deste estudo ajudará a transformar vantagens comparativas em vantagens competitivas, acelerando o processo de desenvolvimento sustentável a médio-longo prazo para o setor e para as empresas de rochas ornamentais do Rio de Janeiro.

Planejamento estratégico, competitividade, maturidade, cenários estratégicos alternativos, desenvolvimento setorial sustentável, estratégias empresariais tecnológicas, comercialização e determinação de valor em empresas em geral e no setor mineral, têm sido pesquisados e estudados nos últimos 25 anos por diversos autores, entre eles: Coutinho \& Ferraz (1994); Hax \& Majluf (1984, 1991); Hayes \& Wheelwright (1979a,b); Margueron (1985); Porter (1980,1986,1989); Rappaport (1986); Roussel et al.(1992).

Este estudo concebeu, estruturou, desenvolveu e aplicou modelo de análise com novas abordagens para a seleção de estratégias naturais (de baixo risco) na análise da posição competitiva de empresas de mineração de rochas ornamentais no município e região metropolitana do Rio de Janeiro. Foi empregada a metodologia da matriz Ciclo de Vida (maturidade do setor industrial versus posição competitiva de um negócio) de planejamento estratégico para as serrarias analisadas (Hax \& Majluf, 1984 e 1991). Também foi realizado o Diagnóstico Estratégico e feitas recomendações sobre possíveis estratégias a serem adotadas por algumas empresas que atuam no setor de serrarias do município do Rio de Janeiro. Finalmente descreveu-se um possível futuro de médio prazo (10 anos) do setor de serrarias de rochas ornamentais no Brasil e no Rio de Janeiro.

\section{Processo Produtivo de Rochas Ornamentais}

As rochas ornamentais no Rio de Janeiro e no Brasil têm sido estudados nos últimos 25 anos por diversos autores, entre eles: ABIROCHAS (2001), Arcoverde (1993), BANDES (1990); Calaes (1994); Chiodi Filho (1995, 2000), CENTRO DE INFORMAÇÕES E DADOS DO RIO DE JANEIRO (CIDE) 
(2001); Coelho (1997, 1998); Coutinho \& Ferraz (1994); COMIG (1999), CONDET (1999); DNPM (1983 a 2001); Menezes (1997); MME/SMM/ DNPM (1994); Oliveira (1998); Silva (1994); Silva (1997); Silva \& Margueron (2002); Vidal (1995).

Dados recentes da Secretaria de Comércio Exterior - SECEX indicam um aumento das exportações de rochas ornamentais do Estado do Rio de Janeiro que, no ano de 2002, alcançaram US\$ 28,2 milhões (96,8\% de produtos acabados, placas polidas e ladrilhos), resultando em um aumento de $29,7 \%$ comparado com 2001, enquanto a média nacional ficou em 21,4\%. Neste período o Estado do Rio de Janeiro participou com 8,5\% da exportação brasileira de rochas ornamentais, que totalizou US\$ 332,2 milhões, aparecendo o Estado do Rio de Janeiro como o terceiro maior exportador do país. Também deve-se mencionar que, nos últimos anos, o Estado do Rio de Janeiro tem demonstrado sua grande vocação para produzir e exportar produtos manufaturados de rochas ornamentais. Por exemplo, em 2002, os manufaturados de rochas ornamentais responderam por 65,8 \% das exportações brasileiras, enquanto no Estado do Rio de Janeiro este número foi de 96,8\%. Conseqüentemente, neste trabalho será dada maior atenção ao beneficiamento das rochas ornamentais no Estado do Rio de Janeiro, no que se refere ao desdobramento de materiais brutos, extraídos das pedreiras em forma de blocos.

O Estado do Rio de Janeiro vem-se recuperando gradualmente da perda de posição competitiva no beneficiamento, acabamento e exportação de manufaturados de rochas ornamentais (granitos e mármores) devido a melhorias que ocorreram na área tributária, na área de infra-estrutura portuária e de transporte, na estrutura de serviços e também devido ao fato de que as empresas têm minimizado os conflitos ambientais de uso e ocupação do solo no Estado do Rio de Janeiro com a importação de blocos de outros Estados. Atualmente, as empresas localizadas no Estado do Rio de Janeiro, produtoras de mármore e granito, estão utilizando aproximadamente 33\% de sua capacidade instalada de pedreiras, e aproximadamente $50 \%$ de sua capacidade instalada de serrarias e marmorarias.

No estudo realizado pela FIRJAN - Federação das Indústrias do Rio de Janeiro - (CONDET,1999), ficou demonstrado que o Estado possui vocações para se revigorar como importante região produtora de rochas ornamentais. Para que isto aconteça será necessário superar vários obstáculos ainda existentes, tais como melhorias nos aspectos estratégicos, econômicos, gerenciais, 


\section{Estratégias Competitivas para Empresas de Rochas Ornamentais na Região Metropolitana do Rio de Janeiro Claudio Margueron \& Edson Farias Mello}

financeiro, competitivos, tecnológicos e mercadológicos das empresas que atuam no setor. Várias ações específicas já foram tomadas, tais como:

- Estudo setorial de rochas ornamentais realizado pela FIRJAN em 1999, que resultou no Plano de Ação para o setor;

- Criação do Fórum Empresarial de Rochas Ornamentais no âmbito do sistema FIRJAN, reunindo empresas e Governo do Estado;

- Convenção de Mármores e Granitos na Arquitetura - Rio Rochas em 2001;

- Catálogo de Rochas Ornamentais do Estado do Rio de Janeiro preparado em 2003;

- Curso de Especialização oferecidos pela UFRJ em parceria com o CETEM e CETEMAG para executivos e gerentes das empresas de rochas ornamentais no Rio de Janeiro e no Espírito Santo em 2005.

Para se ter sucesso nos negócios com rochas ornamentais é necessário o conhecimento de vários segmentos do setor industrial: geologia, caracterização tecnológica, lavra, transporte, beneficiamento e vendas (Figura 1). Só se pode determinar a viabilidade técnica e econômica de pedreiras de rochas ornamentais após concluir certas etapas preliminares, como exploração geológica regional, pesquisa geológica de detalhe e amostragem. A determinação de reservas é feita com furos de sondagem. No caso de rochas ornamentais também são necessários testes de serragem e polimento. Após a cubagem da jazida é realizado o planejamento de lavra. 
Estratégias Competitivas para Empresas de Rochas Ornamentais na Região Metropolitana do Rio de Janeiro

Claudio Margueron \& Edson Farias Mello

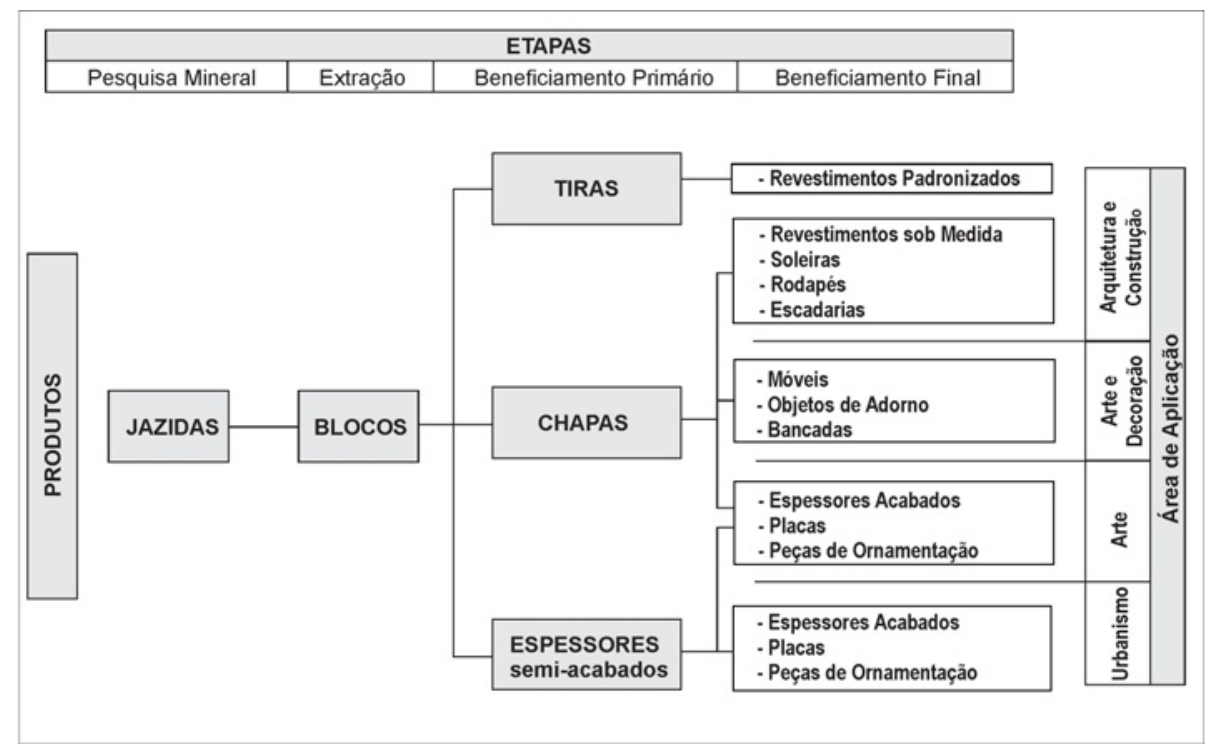

Figura 1 Etapas e Principais Produtos na Indústria de Rochas Ornamentais

O Brasil possui um enorme potencial geológico para a produção de rochas ornamentais (especialmente granitos) de variados padrões estéticos. Existem muitos métodos de lavra para rochas ornamentais usados no mercado: lavra de matacões, lavra por bancadas, lavra por painéis verticais, lavra por desabamento e lavra subterrânea. Aspectos técnicos e econômicos são considerados na escolha do método a ser usado. A lavra de matacões tem o menor custo de produção, mas causa grandes danos ambientais.A lavra de maciços rochosos tem maior custo de produção, mas causa menores danos ao meio ambiente. O beneficiamento de rochas ornamentais é o desdobramento de materiais brutos extraídos nas pedreiras na forma de blocos, e pode ser subdividido em processo de beneficiamento primário e secundário (Figura 2). O beneficiamento primário é entendido como o processo de obtenção de chapas com espessuras variadas em unidades industriais chamadas serrarias, enquanto o beneficiamento secundário (corte e acabamento de peças) é realizado nas marmorarias. 


\section{Estratégias Competitivas para Empresas de Rochas Ornamentais na Região Metropolitana do Rio de Janeiro Claudio Margueron \& Edson Farias Mello}

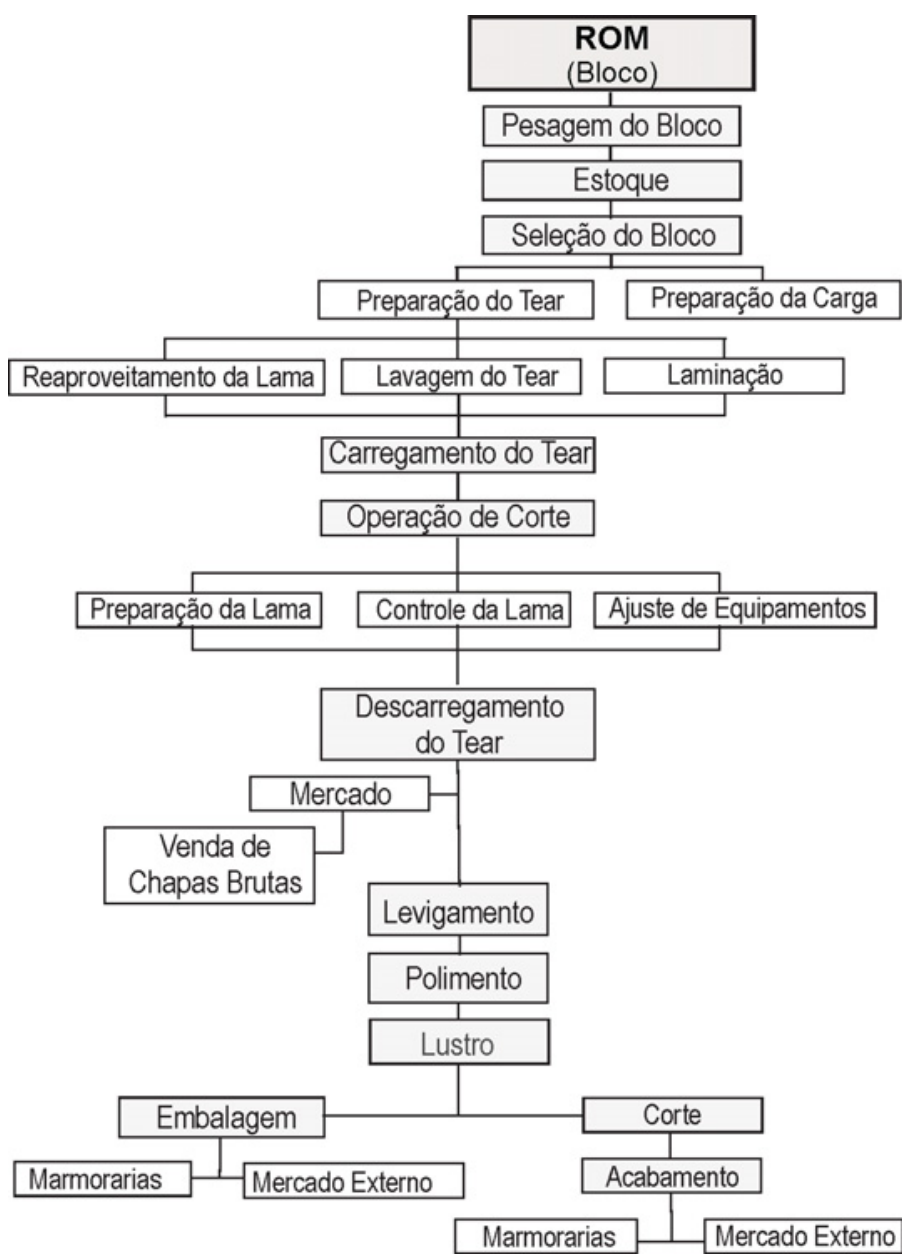

Figura 2 Fluxograma do Processo de Beneficiamento Primário e Secundário de Rochas Ornamentais

Existem empresas integradas verticalmente nas quais a serraria e a marmoraria estão juntas na mesma unidade industrial. Há também empresas que só possuem serraria, outras que só possuem atividades de marmoraria. São três os métodos básicos para fazer o desdobramento de blocos produzidos nas pedreiras: corte com talha-blocos, corte com fio diamantado e corte com tear multilâminas. O talha-blocos é um maquinário de serragem com discos 
diamantados usados para produtos padronizados (lajotas) no aproveitamento de blocos menores que o tamanho padrão (entre 5 e $10 \mathrm{~m}^{3}$ ). O corte com fio diamantado é aplicado basicamente ao esquadrejamento de blocos e de peças curvas. $\mathrm{O}$ tear de multilâminas é o equipamento de corte de blocos mais antigo e mais utilizado para produção de chapas. Este tear possui o menor custo de produção e a mais alta produtividade de chapas em grandes dimensões ( 1 a $2 \mathrm{~m}$ de largura e 2 a 3,5m de comprimento).

A serragem nos teares é auxiliada por uma polpa de água, cal e granalha, despejada continuamente sobre a carga, para otimização do corte e resfriamento das lâminas. Os teares importados da Itália são melhores que os brasileiros, pois oferecem mais produtividade e maior qualidade nos produtos. Esta falta de competitividade dos teares fabricados e usados no Brasil é causada por vários fatores, entre os quais a baixa qualificação da mão-de-obra brasileira na operação e manutenção e a inadequadas condições e controle de instalação.

Depois de serradas nos teares ou talha-blocos, as chapas e outras peças passam por um acabamento final através dos processos de levigamento, polimento e lustro, ou do apicoamento e flameamento - Beneficiamento Secundário. As técnicas de apicoamento e flameamento quando aplicadas a certos tipos de material produzem resultados estéticos e práticos diferentes dos do polimento, no qual são usados vários tipos de politrizes: manuais, de ponte e multicabeça. O corte final das chapas ou peças usa cortadeiras que utilizam o disco diamantado.

\section{Planejamento Estratégico das Serrarias de Rochas Ornamentais}

Nos últimos 15 anos diminuíram os investimentos empresariais no Estado e no município do Rio de Janeiro devido a mudanças nas legislações ambiental e tributária. Tais mudanças e a falta de dados e informações estratégicas, econômicas, geológicas, técnicas e ambientais no desenvolvimento de projetos de investimentos levaram à perda da posição competitiva do Rio de Janeiro e ao fechamento de várias pedreiras, serrarias e marmorarias. Melhorias têm ocorrido desde 1999, porém ainda existem obstáculos no planejamento estratégico e na gestão das empresas.

Neste estudo foram identificados e avaliados estrategicamente os grupos empresariais do Rio de Janeiro que operam pedreiras (dentro e fora do Estado do Rio), serrarias e marmorarias com melhores condições técnicas, 
econômicas, financeiras, administrativas e estratégicas para fazerem parcerias estratégicas ou competitivas com empresários interessados em investir no setor de rochas ornamentais no Rio de Janeiro e no Brasil. As empresas analisadas foram: Thor, Brasilstone, Rio Segran, Gutimpex, Cavaliere, Belmonte, Realbrasil e Marcovaldi. Optou-se neste estudo pelo enfoque na fase de beneficiamento primário (serrarias), pois se trata da grande vocação do Rio de Janeiro nos últimos anos e da fase de maior agregação de valor ao produto que tem enfrentado certas dificuldades de competitividade no mercado interno e externo.

A empresa Silva Areal não foi considerada na análise, pois o grupo empresarial desativou sua serraria recentemente. Seus equipamentos (teares) foram vendidos como sucata, pois já estavam obsoletos. A Silva Areal chegou a ter no passado uma capacidade instalada de produção de chapas de granito de $10.500 \mathrm{~m}^{2} / \mathrm{mês}$. Também não participou de nossa análise a Sociedade MARMÍFERA Brasileira Limitada constituída em 1929 que tem uma serraria pequena (3.000 m²/mês de capacidade instalada) e que há muitos anos tem adotado com sucesso uma grande opção estratégica de segurar-se em um nicho, pois ela só produz o tradicional Azul Bahia. De sua produção de 2.500 $\mathrm{m}^{2} / \mathrm{mês}, 70 \%$ é destinada para exportação e $30 \%$ para o mercado interno (grandes construtoras como GAFISA, João Fortes, Carvalho Hosken, etc.). O faturamento da MARMÍFERA provém 30\% da venda de blocos e $70 \%$ da venda de chapas do Azul Bahia. O grupo tem uma capacidade instalada de $3.000 \mathrm{~m}^{2} / \mathrm{mês}$ para acabados. As pedreiras do Azul Bahia são operadas pela Marmífera Serviços e Construções Limitada, que tem parceria com a Mineração Apolo (Grupo Badin) no Estado da Bahia.

\subsection{Metodologia Específica e Detalhada de Planejamento Estratégico}

A estruturação de um sistema de planejamento estratégico implica primeiramente na identificação das áreas de negócios em que as empresas desenvolvem suas atividades. A partir daí são estudados os mercados em que atuam e seus posicionamentos em relação à concorrência. Neste estudo foram selecionadas as serrarias de rochas ornamentais e cobertas apenas as 8 principais empresas produtoras de chapas de granito no município e na região metropolitana do Rio de Janeiro. Usou-se a metodologia do Ciclo de Vida na análise estratégica específica e detalhada. Outras metodologias, tais como a Matriz de Crescimento - Fatia de Mercado ou a Matriz de Lucratividade também poderiam ter sido utilizadas. Todas estas metodologias de análise estratégica levam a resultados e conclusões similares. 


\section{Estratégias Competitivas para Empresas de Rochas Ornamentais na Região Metropolitana do Rio de Janeiro \\ Claudio Margueron \& Edson Farias Mello}

No preenchimento das várias tabelas, planilhas e matrizes, foram feitas muitas entrevistas, discussões e debates com dezenas de especialistas do setor de rochas ornamentais no Estado do Rio de Janeiro, particularmente consultores, professores, pesquisadores, proprietários e executivos de pedreiras-serrarias-marmorarias, pesquisadores, alunos de graduação, pós-graduação, cursos de especialização, sindicalistas, funcionários públicos estaduais e federais. Foram também utilizadas informações e dados publicados na Internet, nas revistas e referências bibliográficas.

A metodologia usada em nossa análise estratégica utilizando a Matriz de Ciclo de Vida tem como fundamentação básica a conjugação de três análises distintas: o estágio de maturidade do ramo industrial (serrarias de rochas ornamentais no município do Rio de Janeiro), as fatias ou participações de mercado das principais empresas concorrentes e os fatores críticos para a obtenção de sucesso.

\subsection{Maturidade do Ramo Industrial - Serrarias}

A análise do grau de maturidade do ramo industrial procura fornecer uma visão geral das perspectivas históricas do mercado estudado (chapas de granito de rochas ornamentais produzidas pelas serrarias para o mercado brasileiro). A idéia é identificar as tendências do ramo industrial dentro de um enfoque evolucionista que parte do estágio embrionário e termina no de envelhecimento, passando pelo crescimento e maturação. Cada fase possui uma dinâmica própria e para cada fator considerado na análise há um grupo de características consistentes com o grau de maturidade daquele ramo industrial. Uma vez considerados todos os itens: taxa de crescimento, potencial, linha de produtos, número de competidores, estabilidade da fatia de mercado, padrões de consumo, facilidades de entrega, tecnologia (Tabela 1); estima-se em termos aproximados em qual estágio se encontra a área de negócios analisada (produção de chapas de granito em serrarias), conforme a seguir: 
Estratégias Competitivas para Empresas de Rochas Ornamentais na Região Metropolitana do Rio de Janeiro

Claudio Margueron \& Edson Farias Mello

\begin{tabular}{|l|c|c|c|c|}
\hline \multirow{2}{*}{\multicolumn{1}{|c|}{ INDICADORES }} & \multicolumn{4}{c|}{ ESTÁGIOS } \\
\hline & Embriônico & Crescimento & Maduro & Envelhecimento \\
\hline Taxa de Crescimento & & $\mathrm{X}$ & & \\
\hline Potencial da Indústria & & $\mathrm{X}$ & & \\
\hline Linha de Produtos & & & $\mathrm{X}$ & \\
\hline Número deConcorrentes & & $\mathrm{X}$ & & \\
\hline Estabilidade do Market Share & & $\mathrm{X}$ & & \\
\hline Padrões de Compra & & $\mathrm{X}$ & & \\
\hline Facilidade de Entrada & & $\mathrm{X}$ & & \\
\hline Tecnologia & & $\mathrm{X}$ & & \\
\hline & & & & \\
\hline & & & & \\
\hline & & & & \\
\hline Média Global & & $\mathrm{X}$ & & \\
\hline
\end{tabular}

Tabela 1 Matriz de Maturidade Industrial para o Mercado do Rio de Janeiro de Chapas de Rochas Ornamentais.

- Taxa de Crescimento: estima-se que a demanda por chapas de rochas ornamentais no mercado regional do Rio de Janeiro cresça acima de uma taxa de $4 \%$ a.a. nesta década, enquanto a taxa de expansão do setor mineral e do PIB brasileiro na média crescerão por volta de $4 \%$ a.a.. Partindo-se dessa informação, o setor de serrarias de rochas ornamentais no Rio de Janeiro se situa no estágio médio de crescimento.

- Potencial da Indústria: Considerando-se as incertezas associadas ao potencial de crescimento deste setor de serrarias e o fato de as perspectivas de demanda estarem excedendo as de oferta, as serrarias do município do Rio de Janeiro se encontram no estágio médio de crescimento.Para fortalecer esta avaliação sabe-se que as serrarias estão se expandindo ou tendo planos de expansão (caso da Brasilstone e outras) e que as perspectivas para as vendas aumentarem no exterior também são boas.

- Linha de Produtos: Estima-se que estão em renovação, sem grande ampliação. Portanto, o setor de serrarias do Rio de Janeiro de acordo com este item se situa no início do estágio maduro.

- Número de Competidores: O número e tipo de serrarias que estão entrando neste setor é instável(diminui e aumenta), tendendo a uma consolidação. Deve-se mencionar a entrada da Brasilstone neste setor e a saída da Silva Areal nestes últimos anos. Portanto, de acordo com este descritor, o setor de serrarias se situa no início do estágio de crescimento. 
- Estabilidade das fatias de mercado (Market-Share): Em função do fato de que os líderes trocam posições e que poucas empresas controlam grandes fatias de mercado, conclui-se que o setor de serrarias se situa no estágio médio de crescimento. Para evidenciar esta classificação, deve-se mencionar que a competição pela participação no mercado de chapas está acirrada entre a Thor, a Rio Segran e a Brasilstone. Nota-se também que as perspectivas de crescimento das pequenas serrarias é pouco provável.

- Padrões de Comprasa: Na medida em que os compradores são agressivos, sensíveis a preço e estão no início do processo de lealdade a fornecedor, conclui-se que o setor de serrarias do Rio de Janeiro se situa no estágio médio de crescimento.

- Facilidade de Entrada no Setor: Devido ao fato de que ainda é fácil a entrada no setor de serrarias (como aconteceu com a Brasilstone em passado recente), mas que a presença de novos competidores é modulada por crescimento, conclui-se que o setor de serrarias do Rio de Janeiro se posiciona no estágio de início de crescimento.

- Tecnologia: Existe um número pequeno de tecnologias competitivas no setor e o desempenho do produto é mais importante que a tecnologia. Portanto, as serrarias se situam no estágio médio de crescimento.

- Média Global: Considerando-se os posicionamentos em todos os fatores que afetam a determinação do grau de maturidade do setor industrial analisado em detalhe, conclui-se que o setor de serrarias de rochas ornamentais, para a produção de chapas no município e na região metropolitana do Rio de Janeiro, se encontra no estágio médio de crescimento.

\subsection{Identificação das Fatias de Mercado das Principais Serrarias}

O valor de produção ou capacidade instalada de cada empresa (neste caso, as serrarias de rochas ornamentais que produzem placas) dividido pelo total produzido ou capacidade instalada total no mercado estudado define a participação no mercado de cada empresa analisada. Aproximadamente 86\% da capacidade instalada das serrarias de rochas ornamentais do Estado do Rio de Janeiro estão localizadas no município e na região metropolitana do Rio de Janeiro. Utilizam-se os valores mais recentes disponíveis para o ano de 2005. A Tabela 2 apresenta as participações de mercado (PM) ou as fatias de mercado das 8 (oito) principais serrarias que produzem chapas de granito atualmente no setor de rochas ornamentais, que correspondem a $84 \%$ das fatias de mercado do ano 2005. Utiliza-se neste projeto a capacidade instalada das serrarias como indicador da produção de chapas no cálculo das participações de mercado (PM) - também denominado fatias de mercado. 
Estratégias Competitivas para Empresas de Rochas Ornamentais na Região Metropolitana do Rio de Janeiro

Claudio Margueron \& Edson Farias Mello

\begin{tabular}{|l|c|c|}
\hline \multicolumn{1}{|c|}{$\begin{array}{c}\text { EMPRESA } \\
\text { (Serraria) }\end{array}$} & $\begin{array}{c}\text { CAPACIDADE INSTALADA DA } \\
\text { SERRARIA (m2/mês) }\end{array}$ & $\begin{array}{c}\text { PARTICIPAÇ̃̃o NO } \\
\text { MERCADO } \\
\text { (PM)Analisado(\%) }\end{array}$ \\
\hline THOR & 35.000 & 21 \\
\hline BRASILSTONE & 20.000 & 12 \\
\hline RIO SEGRAN & 25.000 & 15 \\
\hline GUTIMPEX & 15.000 & 9 \\
\hline CAVALIERE & 14.450 & 7 \\
\hline BELMONTE & 12.000 & 7 \\
\hline REAL BRASIL & 12.000 & 0 \\
\hline SILVA AREAL & 0 & 5 \\
\hline MARCOVALDI & 8.750 & 16 \\
\hline VÁRIAS OUTRAS SERRARIAS & 20.800 & $100 \%$ \\
\hline Total Analisado(Região Metropolitana) & 163.000 & \\
\hline
\end{tabular}

Tabela 2 Capacidade Instalada de Produção de Chapas de Granito das Principais Serrarias no Município e na Região Metropolitana do Rio de Janeiro, Ano 2005.

Analisando-se a evolução histórica das posições das serrarias investigadas nos últimos 5 anos, nota-se que, antes do fechamento da serraria da Silva Areal e da inauguração e operação da serraria da Brasilstone, o município e a região metropolitana do Rio de Janeiro já tinham aproximadamente os mesmos 86\% da capacidade instalada do Estado do Rio de Janeiro. Portanto, não ocorreram modificações na capacidade instalada das serrarias no município. Neste período de tempo também foram desativadas as serrarias Moledo, Marvima e São Sebastião, que eram de pequeno porte. Nestes últimos anos a Marcovaldi foi arrendada, a Gutimpex atualmente opera abaixo da sua capacidade e a Belmonte parece estar enfrentando vários problemas.

Comparando as fatias de mercado das várias serrarias no município do Rio de Janeiro verificou-se que a Brasilstone, para obter os $12 \%$ de sua fatia de mercado nos últimos anos até o ano de 2005, conquistou aproximadamente 7 pontos percentuais da Silva Areal e alguns poucos pontos percentuais ( 0 a $2 \%)$ da Thor, Rio Segran, Gutimpex, Cavaliere, Belmonte, Real Brasil e Marcovaldi.

Como já é fato conhecido, a Thor e a Brasilstone deverão em curto prazo aumentar suas capacidades instaladas de produção de chapas nas serrarias, obtendo maiores percentuais de fatias de mercado. 
Os principais candidatos a perderem mais percentuais de suas fatias de mercado são Gutimpex, Belmonte e Marovaldi que estão atualmente enfrentando vários tipos de problemas.

\subsection{Análise dos Fatores Críticos de Sucesso (FCS) no Segmento de Mercado de Chapas de Rochas Ornamentais}

A realidade de cada ramo industrial e de cada mercado possui características específicas que precisam ser analisadas de forma diferenciada. Neste sentido, identificam-se primeiramente quais são os fatores críticos de sucesso (FCS) para um bom desempenho da empresa (serraria) no segmento do mercado analisado (município e região metropolitana do Rio de Janeiro). Na Tabela 3 estão listados 10 (dez) fatores críticos de sucesso para o setor de serrarias de rochas ornamentais.

Identificaram-se os fatores críticos de sucesso e os pesos a estes itens de acordo com a sua importância para as serrarias de rochas ornamentais na região escolhida para este trabalho em entrevistas e debates que foram feitos com vários especialistas em rochas ornamentais. Esta lista de FCS e seus pesos (em \%) aparecem na Matriz de Avaliação de Concorrentes - Serrarias (Tabela 3). A definição dos fatores críticos de sucesso e a atribuição de pesos foi implementada após detalhados levantamentos, debates e acordos. A realidade do mercado de chapas de rochas ornamentais sugere a preponderância dos seguintes FCS para uma boa performance competitiva das serrarias que operam no setor: custo de produção, tecnologia, capacidade financeira, sistemas e capacidade gerencial, contato com clientes e outros FCS (assistência e suporte técnico, qualidade, prazo de entrega, integração vertical e confiabilidade, pontualidade, reputação e imagem) (Quadro 1).

Na análise da Matriz de Avaliação de Concorrentes - Serrarias (Tabela 3) observa-se que a avaliação dos especialistas dada para as serrarias de rochas ornamentais da região metropolitana do Rio de Janeiro mostra a seguinte distribuição: 6,25\% de notas máximas (5); 20\% de notas 4; 31,25\% de notas 3; $30 \%$ de notas 2 e $12,50 \%$ de notas mínimas (1).

Pode-se mencionar que, das 80 notas dadas pelos especialistas nos vários fatores críticos de sucesso (FCS), 5 notas foram excelentes. (Nota 5: capacidade financeira da Brasilstone, qualidade dos produtos da Brasilstone, conta- 
Estratégias Competitivas para Empresas de Rochas Ornamentais na Região Metropolitana do Rio de Janeiro

Claudio Margueron \& Edson Farias Mello

\begin{tabular}{|c|c|c|c|c|c|c|c|c|c|c|c|c|}
\hline \multirow{10}{*}{ 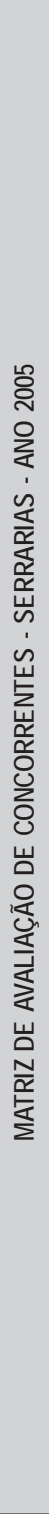 } & $\stackrel{\grave{c}}{F}$ & $\nabla$ & م & n & $\nabla$ & $\nabla$ & $m$ & $\forall$ & $\nabla$ & $\nabla$ & م & $\underset{\sim}{\stackrel{\sim}{\sim}}$ \\
\hline & 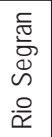 & $\nabla$ & $\nabla$ & $\nabla$ & $m$ & $m$ & $m$ & $m$ & m & $m$ & $\rightarrow 1$ & $\begin{array}{l}\text { m } \\
\text { m }\end{array}$ \\
\hline & 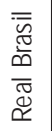 & $m$ & $m$ & $m$ & $m$ & $m$ & $m$ & $\sim$ & m & $m$ & $m$ & 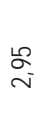 \\
\hline & 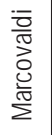 & -1 & -1 & -1 & $\sim$ & $\sim$ & $\sim$ & $\rightarrow$ & $\neg$ & $\neg$ & $\rightarrow$ & $\stackrel{\text { 욕 }}{\rightarrow}$ \\
\hline & 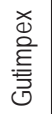 & $\sim$ & $\sim$ & $\sim$ & $m$ & $m$ & $m$ & $m$ & $\sim$ & $\sim$ & $\nabla$ & $\stackrel{\text { q }}{\sim}$ \\
\hline & 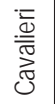 & $\sim$ & $\sim$ & $\sim$ & $\sim$ & $\sim$ & $m$ & $\sim$ & $\sim$ & $\sim$ & $\nabla$ & $\stackrel{\mathscr{N}}{\sim}$ \\
\hline & $\begin{array}{l}\frac{\Phi}{0} \\
\frac{0}{\bar{N}} \\
\frac{\pi}{\omega}\end{array}$ & $\forall$ & $\nabla$ & $\nabla$ & $m$ & เn & $m$ & $\nabla$ & 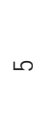 & $\nabla$ & $m$ & 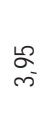 \\
\hline & 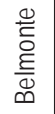 & $\sim$ & -1 & $\sim$ & $\sim$ & $\sim$ & $\sim$ & $\sim$ & $\neg$ & $\sim$ & $m$ & $\underset{-}{\stackrel{8}{-}}$ \\
\hline & $\begin{array}{l}\mathscr{c} \\
0 \\
0 \\
\alpha \\
\alpha\end{array}$ & ठें & ఫे & ఫ్తి & ถิ & เิ๋ & เิ้ & เั้ & ఫ్తి & ه్ㅇ & ఫें & ठ্े \\
\hline & 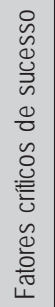 & 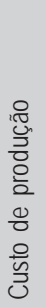 & 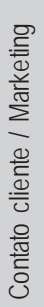 & 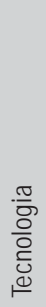 & 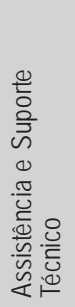 & $\begin{array}{l}\frac{0}{\pi} \\
\frac{\pi}{.0} \\
\frac{0}{\tilde{J}} \\
0\end{array}$ & 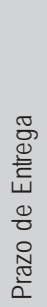 & 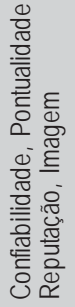 & 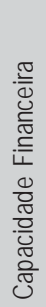 & 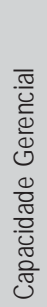 & 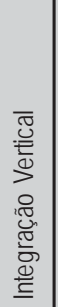 & 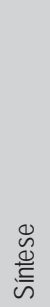 \\
\hline
\end{tabular}

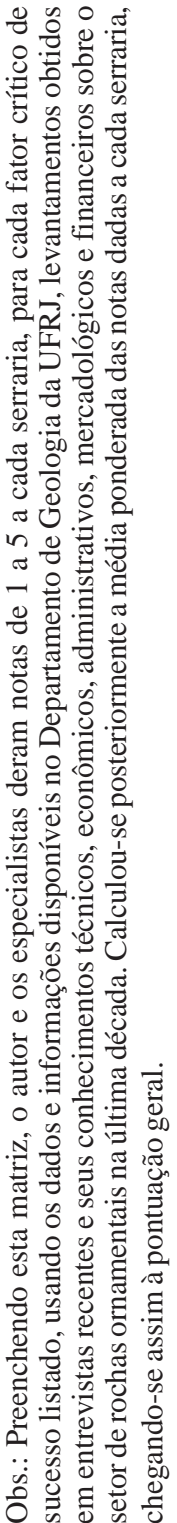

Tabela 3 Matriz de avaliação de concorrentes - serrarias - ano 2005 
to cliente/marketing da Thor, tecnologia da Thor e integração vertical da Thor). Estes são tópicos e áreas que devem servir de exemplo para as outras serrarias. Os especialistas deram 16 notas boas (nota 4) para muitos itens de fatores críticos de sucesso. A Thor, a Brasilstone e a Rio Segran obtiveram várias destas avaliações boas. A grande maioria (49) das notas das avaliações dos especialistas foram razoáveis (nota 3 ) e ruim (nota 2). A maioria das avaliações fracas (nota 1) foi dada a Marcovaldi.

\subsection{Síntese da Posição Competitiva das Serrarias Produtoras de Cha- pas de Rochas Ornamentais}

Na determinação da posição competitiva das serrarias de rochas ornamentais foram utilizados os valores absolutos (ABS) das variáveis-chave: participações no mercado (PM) e dos fatores críticos de sucesso (FCS) obtidos nas análises descritas anteriormente (Quadro 1). Os valores relativos (REL) referentes às participações no mercado e aos fatores críticos de sucesso foram obtidos dividindo-se o maior valor absoluto encontrado pelo segundo maior obtendo-se o maior valor relativo. Os demais valores relativos foram calculados dividindo-se a pontuação da serraria pelo valor da que obteve maior escore. Uma vez definidos os valores relativos para as serrarias analisadas nos tópicos de Fatores Críticos de Sucesso (FCS) deve-se então atribuir pesos a estas duas variáveis-chave. Conforme a importância que possuíram no estudo em questão (exemplo: 50 a 50\%, 70 a 30\%, 60 a 40\%, etc.) calcula-se então, nova média em função destes pesos e dos valores relativos anteriormente encontrados. Os números finais mostrarão o posicionamento competitivo das serrarias no eixo vertical correspondente ao da maturidade do ramo industrial.

Para se obterem os valores relativos (REL) das participações no mercado e dos fatores críticos de sucesso, divide-se o maior valor absoluto encontrado pelo segundo maior obtendo-se o maior valor relativo. Os demais valores relativos são calculados dividindo-se a pontuação da serraria pelo valor da que obteve maior escore.

Na determinação da posição competitiva das serrarias de rochas ornamentais foram utilizados os valores absolutos (ABS) das variáveis-chave: participações no mercado (PM) e dos fatores críticos de sucesso (FCS). No caso específico das serrarias de rochas ornamentais na região metropolitana do Rio de Janeiro, por se tratar de um setor de atividade industrial na fase de crescimento, conclui-se que os fatores críticos de sucesso (FCS) deveriam ter um 


\section{Estratégias Competitivas para Empresas de Rochas Ornamentais na Região Metropolitana do Rio de Janeiro \\ Claudio Margueron \& Edson Farias Mello}

Custo de Produção: este é o fator mais importante porque define a viabilidade econômica da operação das serrarias. As variações no preço de venda das chapas provocam, eventualmente, a abertura ou fechamento das serrarias e/ou a maior ou menor utilização da capacidade instalada e/ou maior ou menor venda no mercado interno vs. externo (outras regiões do Brasil e/ou mercado de exportação). Além disso, empresas (serrarias) com reduzidos custos de produção possuem importante vantagem competitiva, porque podem apresentar lucros maiores nas fases boas e resistir melhor a fases em que o preço é baixo. A política dos governos municipal, estadual e federal em relação às serrarias de rochas ornamentais é outro importante fator para a definição da economicidade da operação. A existência de subsídios, incentivos fiscais, investimentos públicos em infraestrutura etc implica num realinhamento da estrutura de custos destas serrarias. A política de exportação do país, assim como a forma como equaciona seus problemas de balança de pagamentos também influenciam as condições nas quais se desenvolve a produção das serrarias no município do Rio de Janeiro.

Tecnologia: o domínio do know-how tecnológico na produção de chapas permite a obtenção de maiores níveis de produtividade, custos menores de produção, melhor qualidade de produto e maior competitividade. $\mathrm{O}$ uso de equipamento importado da Itália incorpora avanços tecnológicos, alto grau de automação dos teares, melhor controle do processo industrial.

Capacidade Financeira: este fator é importante porque possibilita às serrarias a aquisição de equipamentos importados que são mais produtivos, mais eficientes e mais automatizados, apesar de mais caros. Deve-se mencionar que para estimular as serrarias na sua modernização, o governo do Estado do Rio de Janeiro desonerou do ICMS as operações de importação de máquinas e equipamentos. Este fator também permite a contratação de um maior número de profissionais bem treinados.

Sistemas e Capacidade Gerencial: este fator está ficando cada vez mais importante, pois o negócio está se tornando cada vez mais competitivo, mais técnico e mais profissionalizado exigindo mais planejamento, orçamentação e controle das operações das serrarias. As serrarias que têm obtido mais lucros, maiores fatias de mercado, melhor qualidade são as que têm sistemas planejados, implantados e gerenciados de controle de serrada, de controle de custos e controle de qualidade.

Contato com clientes - canais de comercialização: este fator é importante no marketing e nas vendas de chapas e outros produtos. As serrarias que têm equipes agressivas de marketing e vendas e canais de comercialização bem planejados e implantados no Brasil e no exterior são as que têm crescido mais nos últimos anos e as que têm obtido mais lucratividade e melhor imagem no mercado.

Quadro 1 Fatores críticos de sucesso (FCS)

peso maior (60\%) que a participação no mercado (40\%) (Tabela 4). Também se pode argumentar que, devido a fatores de competição cada vez maiores na venda de chapas de rochas ornamentais a um setor industrial em crescimento, poder-se-ia dar um peso maior (70\%) para os fatores críticos de sucesso (FCS) em relação à participação no mercado, que nesta nova situação receberia o peso de $30 \%$. Se esta simulação tivesse sido realizada, haveria algumas pequenas modificações no posicionamento competitivo das serrarias analisadas. 
Desta forma, conclui-se que a Thor está em uma posição competitiva muito forte liderando com folga todas as serrarias do município do Rio de Janeiro (Tabela 4 e Figura 3). A Brasilstone e a Rio Segran, em posição competitiva favorável média, também estão bem. A Real Brasil, na posição sofrível positiva, é a quarta colocada. A Cavaliere e a Gutimpex dividem a quinta posição seguidas pela Belmonte. A Marcovaldi está no último lugar, bem distanciada da serraria à sua frente.

\begin{tabular}{|c|c|c|c|c|c|c|}
\hline \multicolumn{7}{|c|}{ SÍNTESE DA POSIÇÃO ESTRATÉGICA } \\
\hline \multirow{2}{*}{ CONCORRENTES } & \multicolumn{2}{|c|}{ MARKET SHARE $40 \%$} & \multicolumn{2}{|c|}{ FATORES DE SUCESSO 60\% } & \multicolumn{2}{|c|}{ SÍNTESE $100 \%$} \\
\hline & ABS & REL & ABS & REL & PESOS & POSIÇÃO \\
\hline THOR & 21 & 1,40 & 4,25 & 1,07 & 1,2 & Forte + \\
\hline BRASILSTONE & 12 & 0,57 & 3,95 & 0,93 & 0,8 & Favorável \\
\hline RIO SEGRAN & 15 & 0,71 & 3,30 & 0,77 & 0,75 & Favorável \\
\hline GUTIMPEX & 9 & 0,42 & 2,50 & 0,56 & 0,50 & Sustentável \\
\hline CAVALIERE & 8 & 0,38 & 2,25 & 0,52 & 0,46 & Sustentável \\
\hline BELMONTE & 7 & 0,33 & 1,90 & 0,44 & 0,39 & Sustentável - \\
\hline REAL BRASIL & 7 & 0,33 & 2,95 & 0,69 & 0,55 & Sustentável + \\
\hline MARCOVALDI & 5 & 0,23 & 1,15 & 0,23 & 0,2 & Fraca \\
\hline \multicolumn{7}{|c|}{$\begin{array}{l}\text { Obs.: 1. Fase de maturidade }=\text { Fase de Crescimento. } \\
\text { 2. Reações entre os resultados (pesos) e as posições competitivas }\end{array}$} \\
\hline 0,0 a 0,1 - fraco - & \multicolumn{2}{|c|}{ 0,3 a 0,4 - sustentável - } & \multicolumn{2}{|c|}{ 0,6 a 0,7 - favorável - } & \multicolumn{2}{|c|}{0,9 a 1,0 - forte - } \\
\hline 0,1 a 0,2 - fraco & \multicolumn{2}{|c|}{0,4 a 0,5 - sustentável } & \multicolumn{2}{|c|}{ 0,7 a 0,8 - favorável } & \multicolumn{2}{|c|}{1,0 a 1,1 - forte } \\
\hline 0,2 a 0,3 - fraco + & \multicolumn{2}{|c|}{0,5 a 0,6 - sustentável + } & \multicolumn{2}{|c|}{ 0,8 a 0,9 - favorável+ } & \multicolumn{2}{|c|}{1,1, a 1,2 - forte +} \\
\hline & & & & & & $>1,2$ - dominante \\
\hline
\end{tabular}

Tabela 4 Síntese da Posição Estratégica do segmento estratégico: chapas de rochas ornamentais no mercado do município do Rio de Janeiro, Ano 2005.

Analisando o posicionamento competitivo das serrarias no eixo vertical da matriz de opções estratégicas (Figura 4) vê-se que apenas a Thor, a Brasilstone e Rio Segran estão em posições negociais confortáveis, pois estão em zona de desenvolvimento natural. A Real Brasil está em posição negocial 
aceitável, porém sujeita a certos riscos e incertezas. Tal situação no futuro dependerá muito das opções estratégicas e programas de ação que ela adotar no presente. Já a situação negocial da Gutimpex, Cavaliere e Belmonte é de grande risco e incerteza quanto a seus futuros. Estas estão em zona de desenvolvimento seletivo e só podem sobreviver se adotarem um número limitado de estratégias seletivamente. Elas estão desequilibradas e podem cair para as zonas de perigo. Estas empresas necessitam de atenção e cuidados especiais e, se não melhorarem a curto prazo, devem recorrer a auxílio de consultores externos. A situação negociável da Marcovaldi é a de doença grave terminal. Ela está arrendada atualmente e deverá rapidamente sair desta zona de perigo em que se encontra através de investimentos e mudanças drásticas e radicais, caso contrário, deverá encerrar suas atividades industriais.

\subsection{Matriz de Posicionamento Estratégico das Serrarias}

Baseada na atual posição competitiva das oito principais serrarias de rochas ornamentais na região metropolitana do Rio de Janeiro e no estágio de maturidade (crescimento médio) do setor de serrarias, foi construída a Matriz de Posicionamento Estratégico das empresas nesta região (Figura 4), onde são apresentadas as quatro famílias de zonas naturais de desenvolvimento. Neste cenário a Thor Granitos, a Rio Segran, a Brasilstone e a Real Brasil estão na zona de desenvolvimento livre ou natural. A Gutimpex, a Cavaliere e a Belmonte estão na zona de desenvolvimento seletivo. A Marcovaldi é a única serraria na zona de virada até provar viabilidade. Após a determinação da posição estratégica das serrarias na Matriz de Posicionamento Estratégico ou Matriz de Opções Estratégicas, formulam-se as estratégias naturais (de baixo risco) que podem ser escolhidas.

As três serrarias (Thor, Brasilstone, e Rio Segran), que se encontram bem posicionadas na zona de desenvolvimento natural ou desenvolvimento livre, podem selecionar uma das seis grandes opções estratégicas recomendadas para esta posição estratégica: iniciar atividades, crescer com a indústria, ganhar posição gradualmente, ganhar posição agressivamente, defender posição ou colher.

A grande opção estratégica recomendada para a Thor Granitos é crescer com a indústria, pois estando colocada na posição competitiva forte+ em um setor em crescimento, ela tem condições de adotar uma grande variedade de amplos programas de ação, tais como mais integração para trás, desenvol- 
Estratégias Competitivas para Empresas de Rochas Ornamentais na Região Metropolitana do Rio de Janeiro

Claudio Margueron \& Edson Farias Mello

\begin{tabular}{|l|c|}
\hline DOMINANTE & THOR \\
\hline FORTE & \multicolumn{2}{|c|}{ BRASILSTONE $\uparrow$} \\
\hline \multirow{2}{*}{ FAVORÁVEL } & RIO SEGRAN \\
& \multicolumn{2}{|c|}{ REAL BRASIL } \\
SOFRIVEL OU \\
SUSTENTÁVEL
\end{tabular}

FASE DE MATURIDADE: CRESCIMENTO

Figura 3 - Posições competitivas das serrarias do segmento estratégico: chapas de rochas ornamentais no mercado do município do Rio de Janeiro - ano 2005. Ascendente (-); descendente ( ${ }^{(}$); estável («)

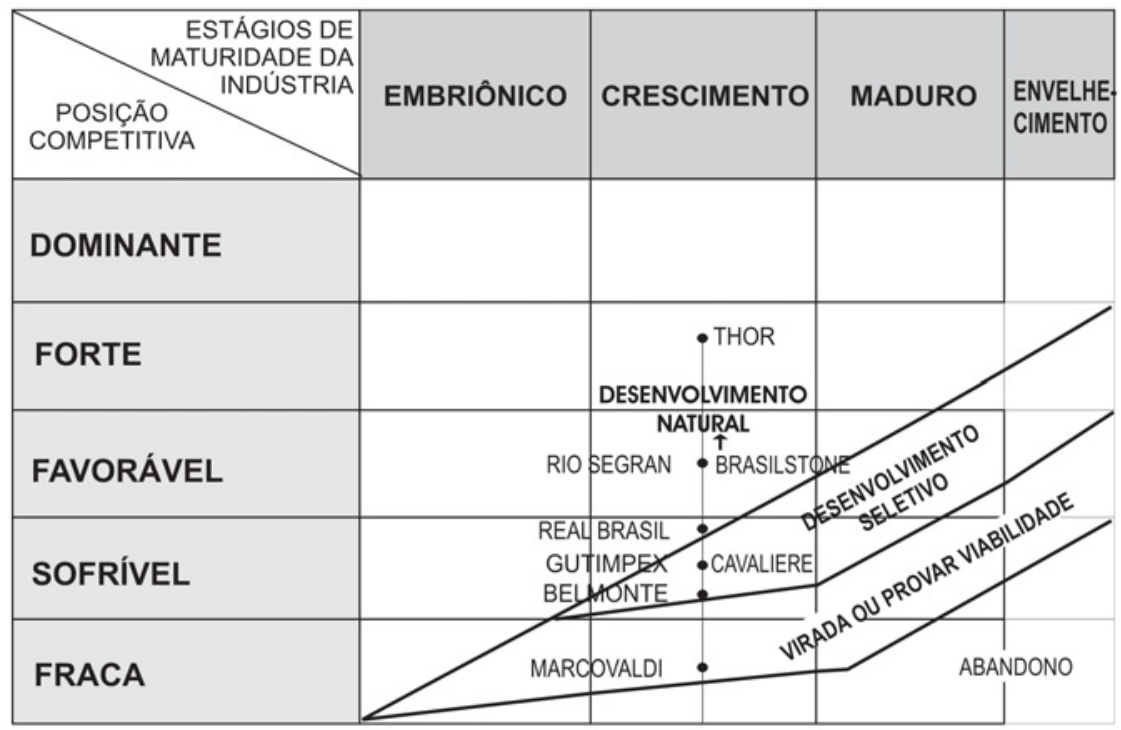

Figura 4 - Matriz de Opções Estratégicas ou de Posicionamento Estratégico para as Principais Serrarias de Chapas de Rochas Ornamentais, Ano 2005. 
ver mais negócios no exterior, desenvolver serrarias no exterior, exportar mais dos mesmos produtos, iniciar licenciamento no exterior, aumentar ainda mais a eficiência nas funções e métodos operacionais, introduzir novos produtos nos mercados para os quais já vende, introduzir os mesmos produtos em novos mercados, aumentar as vendas dos mesmos produtos nos mercados já servidos. Todos estes dez amplos programas de ação acima mencionados são estratégias naturais de baixo risco.

Deve-se também mencionar que principalmente os enfoques-estratégias de marketing/vendas, e de expansão geográfica nacional e internacional são os mais recomendados para o setor industrial em fase de crescimento numa primeira análise. Em casos especiais podem ser considerados enfoques de produção como segunda prioridade. Dos dez amplos programas de ação acima mencionados o menos recomendado dos listados é o de "eficiência gerencial" (especificamente: aumentar ainda mais a eficiência nas funções e métodos operacionais). Os enfoques estratégicos de produção só devem ser adotados após análises mais aprofundadas. Este é o caso dos amplos programas de ação do tipo mais integração para trás, e desenvolver serrarias no exterior.

De início e prioritariamente só seis amplos programas de ação devem ser analisados e debatidos pela Thor: desenvolver mais negócios no exterior; exportar mais dos mesmos produtos; iniciar licenciamento no exterior; introduzir novos produtos nos mercados para os quais já vende; introduzir os mesmos produtos em novos mercados; aumentar as vendas dos mesmos produtos nos mercados já servidos.

Apesar de a Brasilstone e a Rio Segran estarem na mesma posição competitiva, são recomendadas grandes opções estratégicas diferentes para cada uma delas, pois a Brasilstone está numa posição competitiva ascendente e a Rio Segran, em uma posição competitiva estabilizada (Figuras 3 e 4). Portanto, a grande opção estratégica recomendada para a Brasilstone é ganhar posição agressivamente porque, estando colocada na posição competitiva favorável em um setor em crescimento, ela tem condições de adotar uma grande variedade de amplos programas de ação, tais como integração vertical para trás, desenvolver mais negócios internacionais, desenvolver serrarias no exterior, investir para ter excesso de capacidade instalada, mais integração vertical para frente, mais penetração nos mercados já servidos, mais eficiência nas funções e métodos em novos mercados, introduzir novos produtos nos mesmos mercados, introduzir os mesmos produtos em novos mercados, melhorar a eficiência tecnológica. 


\section{Estratégias Competitivas para Empresas de Rochas Ornamentais na Região Metropolitana do Rio de Janeiro \\ Claudio Margueron \& Edson Farias Mello}

Todos estes onze amplos programas de ação recomendados para a Brasilstone são estratégias naturais de baixo risco. No entanto, não quer dizer que todos eles devam ser adotados ao mesmo tempo; devem ser analisados, classificados e priorizados no tempo, de acordo com os recursos financeiros e humanos disponíveis. O enfoque estratégico de produção pode ser considerado quando existem indicações da maturidade estar avançando do estágio de crescimento médio para o estágio de crescimento avançado. Com este enfoque, vêse que o número de programas de ação de baixo risco para a Brasilstone diminui numa análise inicial de onze alternativas para seis. É possível que alguns enfoques estratégicos específicos de produção também possam ser considerados. A experiência ensina que, normalmente enfoques estratégicos de produção e de eficiência gerencial e operacional são mais indicados no estágio maduro e/ ou no estágio de crescimento próximo do maduro.

Portanto, prioritariamente só cinco amplos programas de ação devem ser analisados e debatidos pela Brasilstone, pois os mesmos são programas de ação estratégica naturais e de baixo risco: desenvolver mais negócios no exterior; mais penetração nos mercados já servidos; introduzir novos produtos em novos mercados; introduzir novos produtos nos mesmos mercados; e introduzir os mesmos produtos em novos mercados.

Caso se identifiquem razões específicas e importantes, como segunda prioridade podem ser analisados em profundidade certos programas de ação com enfoque de produção, tais como: integração vertical para trás; desenvolver serrarias no exterior; investir para ter excesso de capacidade instalada; e mais integração vertical para a frente.

Estes programas de ação relacionados como segunda prioridade já oferecem maior risco de fracasso e só devem ser implementados após profundos estudos e análises e com cuidados especiais.

A grande opção estratégica recomendada para a Rio Segran é ganhar posição gradualmente, já que nesta posição competitiva favorável ela tem condições de adotar um ou mais dos amplos programas de ação tal como integração vertical para a frente, abrindo mais marmorarias, aumentando ainda mais a sua penetração nos mercados e introduzindo os mesmos produtos em novos mercados. O enfoque estratégico de produção (integração vertical para a frente abrindo marmorarias) só deve ser considerado em situações bem específicas e bem analisadas, pois ele é mais fortemente recomendado quando a maturidade do setor industrial é crescimento avançado ou maduro ou envelhecido. Portanto, inicialmente só dois amplos programas de ação estratégicos devem ser analisados para a Rio Segran: aumentar ainda mais sua penetração nos mercados 


\section{Estratégias Competitivas para Empresas de Rochas Ornamentais na Região \\ Metropolitana do Rio de Janeiro \\ Claudio Margueron \& Edson Farias Mello}

regionais, nacionais e internacionais de chapas de rochas ornamentais e introduzir os mesmos produtos de chapas de rochas ornamentais, que já comercializa, em novos mercados regionais, nacionais e internacionais.

Como as serrarias da Gutimpex, da Cavaliere, da Belmonte se encontram na zona de desenvolvimento seletivo elas podem selecionar uma das três grandes opções estratégicas: encontrar um nicho (ninho protegido), explorar um nicho, agüentar-se em um nicho. A grande opção estratégica recomendada para a Gutimpex é procurar um nicho (ninho protegido), pois sua posição competitiva é descendente (Figura 3) e talvez possa estabilizar-se posicionando-se em um ninho protegido. Depois de estabilizada é que a serraria poderá melhorar sua posição competitiva. Nesta posição competitiva sustentável descendente a Gutimpex tem condições de adotar uma variedade de amplos programas de ação, tais como: mais integração vertical para trás, mais integração vertical para frente, iniciar desenvolvimento de novos mercados, mais penetração de mercado, racionalização de mercado, racionalização da linha de produtos, introduzir os mesmos produtos em novos mercados.

No estágio de crescimento em que se encontra o setor de serrarias de rochas ornamentais devem ser priorizados principalmente os enfoques estratégicos de marketing/vendas e de expansão geográfica (nacional e internacional). O enfoque estratégico de produção deve ser uma segunda prioridade e só deve ser adotado em casos especiais após a análise mais aprofundada.

Portanto, quatro amplos programas de ação estratégica devem ser prioritariamente analisados pela Gutimpex: iniciar o desenvolvimento de novos mercados para chapas no Brasil e no exterior; obter maior penetração de mercado; realizar uma racionalização de mercado; e introduzir os mesmos produtos de chapas de rochas ornamentais em novos mercados.

A grande opção estratégica recomendada para a Belmonte é procurar um nicho, pois sua posição competitiva é descendente (Figura 3) e deve tentar estabilizar-se o mais rapidamente possível para não cair da posição competitiva sustentável para fraca, que causaria uma mudança nas suas grandes opções estratégicas e seus respectivos amplos programas de ação. Nesta atual posição competitiva sustentável a Belmonte tem condições de adotar uma variedade de amplos programas de ação, tais como: mais integração vertical para trás, mais integração vertical para frente, iniciar desenvolvimento de novos mercados, maior penetração de mercado, racionalização de mercado, racionalização da linha de produtos, introdução dos mesmos produtos em novos mercados. 


\section{Estratégias Competitivas para Empresas de Rochas Ornamentais na Região Metropolitana do Rio de Janeiro \\ Claudio Margueron \& Edson Farias Mello}

Tudo o que já foi discutido anteriormente no caso da Gutimpex também se aplica aqui.

Portanto, inicialmente, apenas quatro amplos programas de ação estratégica devem ser inicial e prioritariamente analisados pela Belmonte: iniciar o desenvolvimento de novos mercados para chapas de rochas ornamentais no Brasil e no exterior; obter maior penetração de mercado; realizar uma racionalização de mercado; introduzir os mesmos produtos (chapas de rochas ornamentais) em novos mercados.

A grande opção estratégica recomendada para a Cavaliere é segurar-se em um nicho, pois sua posição competitiva está estabilizada no momento. Nesta atual posição competitiva sustentável a Cavaliere tem condições de adotar uma variedade de amplos programas de ação, tais como: desenvolvimento de operações no exterior, racionalização da distribuição, eficiência nas funções e métodos operacionais, racionalização da produção, manutenção dos mesmos produtos nos mesmos mercados. Portanto, prioritariamente, apenas dois amplos programas de ação estratégica devem ser analisados pela Cavaliere: racionalização da distribuição e manter os mesmos produtos de chapas de rochas ornamentais nos mesmos mercados.

A serraria da Marcovaldi é a única que se encontra na zona de Provar Viabilidade e, conseqüentemente, ela pode selecionar uma das quatro grandes opções estratégicas: recuperar o tempo ou o espaço perdido, renovar, dar a volta por cima, prolongar a existência. A grande opção estratégica recomendada para a Marcovaldi é dar a volta por cima, já que sua posição competitiva está estabilizada (Figura 3), agora que foi arrendada para dois grupos empresariais (Giemac e Comepre).

Nesta atual posição competitiva fraca a Marcovaldi tem condições de adotar uma variedade de amplos programas de ação, tais como: racionalização da distribuição, mais penetração nos mercados, racionalização dos mercados, eficiência nas funções e métodos operacionais, racionalização da produção, racionalização da linha de produtos, melhoria da eficiência tecnológica e da produção, eficiência no tradicional corte de custos de produção e comercialização.

Portanto, prioritariamente apenas três amplos programas de ação estratégica devem ser analisados pelos arrendatários da Marcovaldi, pois os mes- 
mos têm baixo risco: racionalização da distribuição; maior penetração nos mercados; e racionalização dos mercados.

Como segunda prioridade podem ser analisados os três amplos programas de ação estratégica com enfoque de produção (que oferecem maior risco): racionalização da produção; racionalização da linha de produtos; melhoria da eficiência tecnológica (de produção).

Os enfoques estratégicos de eficiência gerencial (eficiência nas funções e métodos operacionais, eficiência no tradicional corte de custo de produção e comercialização) não são prioridades e não são normalmente recomendados para empresas que estão na fase de crescimento na escala de maturidade do setor industrial analisado.

\section{O Futuro do Setor de Serrarias de Rochas Ornamentais no Brasil e no Rio de Janeiro}

Na próxima década, os Estados Unidos da América do Norte continuarão sendo o grande mercado consumidor de chapas e produtos acabados de rochas ornamentais no mundo. Este mercado continuará exigindo produtos da melhor qualidade e preços mais atrativos. Portanto, a competição para fornecer este mercado será muito acirrada e só sobreviverão as empresas competitivas. As empresas da China, Itália, Brasil, Espanha deverão estar competindo acirradamente para vender e lucrar como fornecedores do mercado dos Estados Unidos da América do Norte. As empresas da China, Itália, Espanha e outros países continuarão importando blocos do Brasil para depois transformálos em suas modernas e competitivas chapas e produtos acabados para o mercado norte-americano. Nos próximos anos um número cada vez maior destas serrarias estrangeiras estará se integrando verticalmente para trás, procurando parcerias com pedreiras e serrarias brasileiras localizadas no Espírito Santo e no Rio de Janeiro, para transformarem os blocos em chapas e produtos acabados no próprio Brasil e, posteriormente, vendê-los aos clientes e consumidores norte-americanos. Isto já está acontecendo com a Marmi Bruno Zanet, Grein, Testi, Antolini, e outras. O objetivo é reduzir os custos de produção de chapas e produtos acabados para se tornarem mais competitivos no mercado consumidor dos Estados Unidos e, conseqüentemente, aumentarem suas respectivas fatias de mercado. A infra-estrutura de produção, transporte, logística e exportação do Espírito Santo já começa a demonstrar sinais de congestionamento nos últimos anos. Como a situação de infra-estrutura no Rio de Janeiro tem 
melhorado, acreditamos que muitas empresas estrangeiras de rochas ornamentais demonstrarão grande interesse em instalar no Rio de Janeiro suas serrarias e infra-estrutura de exportação, através de investimentos em novas fábricas, de parcerias com grupos empresariais já existentes e da compra de empresas que já operam na região Metropolita a do Rio de Janeiro.

A análise dos dados e informações estratégicas das serrarias de rochas ornamentais localizadas no Rio de Janeiro, incluindo a IMIL, que está localizada na região norte do Estado do Rio de Janeiro (Tabelas 5 e 6) permite concluir que as principais serrarias de rochas ornamentais candidatas a parcerias com grupos investidores internacionais podem ser classificados na seguinte seqüência: Brasilstone, Rio Segran, Thor, Gutimpex, Imil, Marcovaldi, Cavaliere, Belmonte, e Real Brasil. Existem poucas (8,8\%) avaliações excelentes, equivalentes à nota 5 , nos vários quesitos usados nesta avaliação de 5 tópicos (situação econômica, situação comercial, controle de serrada, controle de custos e controle de qualidade). O percentual das avaliações boas é de 20\%. Existe também um percentual de 28,8\% tanto nas avaliações razoáveis como nas ruins e pouquíssimas $(13,3 \%)$ de avaliações fracas. Portanto, podemos verificar que $29 \%$ das avaliações dos principais quesitos das serrarias são boas e excelentes. Aproximadamente 58\% das avaliações das serrarias de rochas ornamentais são razoáveis e ruins. Apenas $13 \%$ das avaliações são fracas. Por fim, pode-se concluir que o setor e a maioria das serrarias de rochas ornamentais se beneficiariam fazendo parcerias com grupos estrangeiros capazes de investir capital, tecnologia, capacidade comercial e de gestão.

\section{Conclusões e Recomendações}

As rochas brasileiras são consideradas exóticas e de rara beleza no mercado internacional, apesar de imporem dificuldades técnicas de beneficiamento. $O$ país possui uma das maiores reservas mundiais e uma enorme variedade de rochas ornamentais. Portanto, mesmo com pouco planejamento e racionalização do processo produtivo (pedreiras, serrarias e marmorarias) é possível ter lucros. Este setor, no Brasil e na região metropolitana do Rio de Janeiro é constituído em grande parte por pequenas empresas familiares, conservadoras, pouco profissionalizadas e que enfrentam problemas de tecnologia, gestão e de recursos humanos e financeiros. Sua maior atividade é a produção e exportação de blocos para os mercados mundiais. 


\section{Estratégias Competitivas para Empresas de Rochas Ornamentais na Região \\ Metropolitana do Rio de Janeiro \\ Claudio Margueron \& Edson Farias Mello}

No município do Rio de Janeiro a produção de blocos tem diminuído desde 1988, devido à Lei Municipal 1358/88 que impôs muitas restrições ambientais a este setor industrial. Com o encerramento das atividades de muitas pedreiras, as serrarias localizadas na região metropolitana do Rio de Janeiro adotaram com sucesso a estratégia de trazer blocos de outros estados. Recomenda-se a continuação desta estratégia no futuro combinada com a abertura de lavras subterrâneas em casos especiais. Muitos acionistas de serrarias do Rio de Janeiro têm investido em pedreiras no Espírito Santo, Minas Gerais, Bahia e outros estados. Conseqüentemente, os empresários do município do Rio de Janeiro concentraram seus esforços na implantação e expansão de serrarias com muito bons resultados, pois a produção de chapas corresponde a uma etapa de agregação de valor ao produto extraído das pedreiras.

Neste trabalho ficaram evidenciadas as deficiências técnicas, econômicas, financeiras, estratégicas e gerenciais das pequenas serrarias localizadas no município e na região metropolitana do Rio de Janeiro, quando competem com similares no exterior (especialmente Itália, Espanha, Alemanha e Estados Unidos) e no Brasil (especialmente São Paulo e Espírito Santo) as quais investem mais em tecnologia de ponta na produção de chapas de rochas ornamentais e na melhoria de seus processos gerenciais. Foi diagnosticado que a falta de tecnologia avançada, a falta de capital, de integração vertical, de qualidade, de maior capacidade de gestão e a pouca profissionalização que afetam a maioria das pequenas serrarias localizadas no município do Rio de Janeiro são os principais obstáculos a serem resolvidos para a melhoria da competitividade das mesmas no contexto nacional e internacional. Também foram identificadas limitações e deficiências nos sistemas de custos das serrarias. Isto dificulta a busca de soluções gerenciais para problemas encontrados no dia-a-dia das empresas que produzem chapas de rocha ornamentais. Outro problema enfrentado pelas serrarias de rochas ornamentais no Brasil e no município do Rio de Janeiro é a redução de receita de exportação como resultado da recente desvalorização do dólar e do aumento de custos representado pela alta do preço do aço, usado como ferramenta no corte de pedras, no óleo combustível e na energia elétrica. Também pesa o fato de que os equipamentos usados no beneficiamento dos blocos são importados da Europa Ocidental, em euros.

Matrizes de competitividade/atratividade, listas de fatores críticos de sucesso (FCS), estratégias naturais, grandes opções estratégicas - programas de ação - estratégias funcionais - planos de ação não devem ser aplicados mecanicamente para realizar resultados automáticos. Planejamento estratégico e gerenciamento se fazem não só com análise, mas também, com julgamen- 


\section{Estratégias Competitivas para Empresas de Rochas Ornamentais na Região Metropolitana do Rio de Janeiro \\ Claudio Margueron \& Edson Farias Mello}

to e experiência. Instrumentos de análise das causas do valor dos negócios não dispensam o uso de julgamento esclarecido e da experiência.

\begin{tabular}{|c|c|c|c|c|c|c|c|c|c|c|c|c|}
\hline \multirow[b]{2}{*}{ Empresas (Serrarias) } & \multicolumn{3}{|c|}{$\begin{array}{c}\text { Integração } \\
\text { Vertical }\end{array}$} & \multirow{2}{*}{$\begin{array}{l}\text { Integração } \\
\text { Horizontal em } \\
\text { Serrarias }\end{array}$} & \multicolumn{3}{|c|}{$\begin{array}{c}\text { Mercado } \\
\text { Exportação }\end{array}$} & \multirow{2}{*}{$\begin{array}{c}\text { Situação } \\
\text { Econômica } \\
\text { Financeira }\end{array}$} & \multirow{2}{*}{$\begin{array}{l}\text { Situação } \\
\text { Gerencial e } \\
\text { Comercial }\end{array}$} & \multirow{2}{*}{$\begin{array}{c}\text { Controle de } \\
\text { Serrada } \\
\text { (Processo) }\end{array}$} & \multirow{2}{*}{$\begin{array}{l}\text { Controle de } \\
\text { Custos }\end{array}$} & \multirow{2}{*}{$\begin{array}{c}\text { Controle } \\
\text { de } \\
\text { Qualidade }\end{array}$} \\
\hline & $P$ & $\mathrm{Se}$ & $M$ & & Bl. & C & A & & & & & \\
\hline THOR & $\mathrm{s}$ & S & S & $\begin{array}{c}\text { Sim no } \\
\text { Espírito Santo }\end{array}$ & $\mathrm{N}$ & $S$ & $S$ & B & $E$ & B & B & B \\
\hline BRASILSTONE & N & S & s & $\mathrm{N}$ & $\mathrm{N}$ & s & $\mathrm{s}$ & E & B & B & B & E \\
\hline RIO SEGRAN & N & S & N & N & $\mathrm{N}$ & S & $\mathrm{N}$ & $R$ & $\mathrm{R}$ & B & B & $R$ \\
\hline GUTIMPEX & s & s & s & N & $\mathrm{N}$ & S & $\mathrm{s}$ & $\mathrm{Ru}$ & $\mathrm{Ru}$ & $\mathrm{Ru}$ & $\mathrm{Ru}$ & $\mathrm{Ru}$ \\
\hline CAVALIERE & s & S & s & N & $\mathrm{N}$ & N & $\mathrm{N}$ & $\mathrm{Ru}$ & $\mathrm{Ru}$ & $\mathrm{Ru}$ & $\mathrm{Ru}$ & $\mathrm{Ru}$ \\
\hline BELMONTE & s & S & s & $\mathrm{N}$ & $\mathrm{N}$ & N & $\mathrm{N}$ & $\mathrm{F}$ & $\mathrm{F}$ & $\mathrm{Ru}$ & $\mathrm{Ru}$ & $\mathrm{Ru}$ \\
\hline REAL BRASIL & N & S & s & N & $\mathrm{N}$ & N & $\mathrm{N}$ & $\mathrm{R}$ & $\mathrm{R}$ & $\mathrm{R}$ & $R$ & $\mathrm{R}$ \\
\hline $\begin{array}{l}\text { MARCOVALDI } \\
\text { (Comepre - Giemac) }\end{array}$ & N & $\mathrm{s}$ & $N$ & $\mathrm{~N}$ & S & $\mathrm{N}$ & $\mathrm{N}$ & $\mathrm{F}$ & $\mathrm{F}$ & $\mathrm{F}$ & $\mathrm{F}$ & $\mathrm{Ru}$ \\
\hline IMIL & $\mathrm{s}$ & s & $N$ & $\mathrm{~N}$ & $\mathrm{~s}$ & $S$ & $\mathrm{~s}$ & $E$ & $\mathrm{R}$ & $R$ & $R$ & $\mathrm{R}$ \\
\hline
\end{tabular}

Tabela 5 Síntese de dados e informações estratégicas das serrarias de rochas ornamentais do Rio de Janeiro - ano de 2005.

\begin{tabular}{|c|c|c|c|c|c|}
\hline & $\begin{array}{l}\text { Classificaão de posião } \\
\text { competitiva - serrarias }\end{array}$ & $\begin{array}{c}\text { Gestão } \\
\text { Profissionalizada }\end{array}$ & $\begin{array}{c}\text { Classificação da } \\
\text { atratividade para } \\
\text { parcerias com } \\
\text { grupos estrangeiros }\end{array}$ & $\begin{array}{l}\text { Possíveis Grandes } \\
\text { Opções } \\
\text { Estratégicas ou } \\
\text { Estratégia do } \\
\text { Negócio }\end{array}$ & $\begin{array}{l}\text { De capital, } \\
\text { tecnologia e } \\
\text { acesso a } \\
\text { mercados }\end{array}$ \\
\hline THOR & 1 & $50 \%$ & 3 & $\begin{array}{l}\text { Crescer com a } \\
\text { indústria }\end{array}$ & Baixa \\
\hline BRASILSTONE & 2 & $50 \%$ & 1 & $\begin{array}{l}\text { Ganhar posição } \\
\text { agressivamente }\end{array}$ & Média \\
\hline RIO SEGRAN & 3 & $50 \%$ & 2 & $\begin{array}{l}\text { Ganhar posição } \\
\text { gradualmente }\end{array}$ & Média \\
\hline GUTIMPEX & 6 & $60 \%$ & 4 & Procurar um nicho & Alta \\
\hline CAVALIERE & 5 & $40 \%$ & 7 & $\begin{array}{c}\text { Segurar-se em um } \\
\text { nicho }\end{array}$ & Alta \\
\hline BELMONTE & 8 & $60 \%$ & 8 & Procurar um nicho & Alta \\
\hline REAL BRASIL & 4 & $40 \%$ & 9 & $\begin{array}{l}\text { Ganhar posição } \\
\text { gradualmente }\end{array}$ & Média \\
\hline MARCOVALDI & 9 & $50 \%$ & 6 & $\begin{array}{l}\text { Dar a volta por } \\
\text { cima }\end{array}$ & Alta \\
\hline IMIL & 7 & $60 \%$ & 5 & $\begin{array}{c}\text { Segurar-se em um } \\
\text { nicho }\end{array}$ & Alta \\
\hline
\end{tabular}

Tabela 6 Informações estratégicas dos grupos empresariais do Rio de Janeiro operam pedreiras, serrarias e marmorarias. 


\section{Referências}

Abirochas 2001. Rochas Ornamentais no século XXI, Grupo de Trabalho CETEM/MCT, CETEM, RJ. 159 p.

Arcoverde, W. L. 1993. Elementos para uma Política do MME de Desenvolvimento do Setor de Granitos e Mármores no Brasil: 1993 - 2000, MME. 12p.

BANDES. 1990. Estudos Básicos e Indicação de Política e Intervenção para o Complexo de Mármore e Granito do Espírito Santo. 22 p.

Calaes, G.D. 1994. Mercado Nacional de Rochas Ornamentais. Série Estudo Econômico sobre Rochas Ornamentais, v. 2, CNI/FIEC/IEL, Fortaleza, CE. 268 p.

Chiodi Filho, C. 1995. Aspectos Técnicos e Econômicos do Setor de Rochas Ornamentais. $\mathrm{n}^{0}$ 28, Série Estudos e Documentos CETEM, CNPq, Rio de Janeiro. 75 p.

Chiodi Filho, C. 2000. Plano de Ação para o Setor de Rochas Ornamentais de Minas Gerais, Revista Rochas de Qualidade, São Paulo, nº 151: 94-100. CENTRO DE INFORMAÇÕES E DADOS DO RIO DE JANEIRO (CIDE). 2001. Anuário Estatístico do Estado do Rio de Janeiro - Vol. 17 - CIDE/ Governo do Estado/RJ, Rio de Janeiro, RJ. 577p.

Coelho, C.M. 1997. Características e Tendências do Setor Industrial de Rochas Ornamentais no Estado do Rio de Janeiro, Boletim IGEO, 29 p.

Coelho, C.M. 1998. Análise Técnica-Econômica-Financeira de Projetos em Rochas Ornamentais no Município do Rio de Janeiro e Região Metropolitana: Estudos de Caso, Dissertação de Mestrado, Departamento de Geologia, IGEO, UFRJ, $153 \mathrm{p}$.

CONDET. 1999. Estudo Setorial de Rochas Ornamentais no Estado do Rio de Janeiro, Diagnóstico e Plano de Ação, FIRJAN, 247 p.

Coutinho, L \& Ferraz, J. C. 1994. Estudos da competitividade da indústria brasileira. Campinas: Unicamp/Papirus. 510 p.

Hax, A. \& Majluf, N. 1984.Strategic Management: An Integrative Perspective, Prentice Hall. 468 p.

Hax, A.; \& Majluf, N. 1991. The Strategy Concept \& Process: A Pragmatic Approach, Prentice Hall. 430 p.

Hayes, R. H. \& Wheelwright, S. C. 1979a Link Manufacturing Process and Product Life-Cyc1e Harvard Business Review, 57 (1): 133-140.

Hayes, R. H.; Wheelwright, S. C., 1979b The Dynamics of Process Products Life Cycles Harvard Business Review, Vol. 57 (2):127-135.

Oliveira, T.M.A. 1998. Avaliação Técnico-Econômica da Extração de Ro- 


\section{Estratégias Competitivas para Empresas de Rochas Ornamentais na Região Metropolitana do Rio de Janeiro Claudio Margueron \& Edson Farias Mello}

cha Ornamental no Município de Santo Antônio de Pádua, Dissertação de Mestrado, UFRJ, IGEO, 157 p.

Porter, M. E. 1986. Estratégia Competitiva - Técnicas para análise da Indústria, Editora Campus, Rio de Janeiro. 362 p.

Porter, M. E. 1989. Vantagem Competitiva, Editora Campus, Rio de Janeiro. $512 \mathrm{p}$.

Rappaport, A. 1986. Creating Shareholder Value: The New Standard for Business Performance, The Free Press. 270 p.

Roussel, P.A.; Saad, K.N.; Bohlin, N. 1992. Pesquisa e Desenvolvimento: Como Integrar P\&D ao Plano Estratégico e Operacional das Empresas como Fator de Produtividade e Competitividade, Makron Books do Brasil Editora Ltda. 198 p.

Silva, E.V.G. 1994. Mercado Internacional de Rochas Ornamentais, Série Estudo Econômico sobre Rochas Ornamentais, VA, CMI/FIEC/IEL, Fortaleza, CE. 515 p.

Silva, R.E.C. 1997. Estudo Geológico-Técnico-Ambiental de uma Pedreira de Rocha Ornamental no Município de Santo Antônio de Pádua $R J$, Dissertação de Mestrado, Rio de Janeiro, UFRJ, 140 p.

Silva, R.E.C. e MARGUERON, C. Nov/Dez 2002. Rochas Ornamentais Panorama Setorial no Estado do Rio de Janeiro, Revista Minérios \& Minerales, p. 46-50.

Vidal, F.W.H. 1995. A Indústria Extrativa de Rochas Ornamentais do Ceará, Dissertação de Mestrado, Escola Politécnica da USP, Departamento de Engenharia de Minas, 178 p. 